\title{
TINA Is Dead: Reflecting on Postcapitalist Futures
}

\author{
Loris Serafino $^{1, *(\mathbb{D})}$ and Fabrizia Ghezzo ${ }^{2}$ \\ 1 School of Engineering, Australian College of Kuwait, West Mishref 40006, Kuwait \\ 2 Lulan Technologies, Science and Technology Park of Peking University, Shenzhen 518100, China; \\ fabrizia.ghezzo2@studio.unibo.it \\ * Correspondence: 1.serafino@ack.edu.kw
}

check for

updates

Citation: Serafino, L.; Ghezzo, F. TINA Is Dead: Reflecting on Postcapitalist Futures. Humans 2021, 1,44-46. https://doi.org/10.3390/ humans1020006

Received: 12 September 2021 Accepted: 10 November 2021 Published: 23 November 2021

Publisher's Note: MDPI stays neutral with regard to jurisdictional claims in published maps and institutional affiliations.

Copyright: (C) 2021 by the authors. Licensee MDPI, Basel, Switzerland. This article is an open access article distributed under the terms and conditions of the Creative Commons Attribution (CC BY) license (https:// creativecommons.org/licenses/by/ $4.0 /)$.

\begin{abstract}
Social sciences in recent years have clearly proven that TINA-There Is No Alternative (to capitalism) - is no longer tenable. Today, alterity to capitalism comes in many forms and blossoms from inside its borders. Ethnographies of experimentations that span from ecovillages and community economies to alternative forms of work, production, and consumption are now countless. One common denominator of these experiences is that communal forms of social relation take over market relations. The main theoretical issue raised by this empirical work is whether this ferment of scattered, small scale alternative ways of organizing economy and society can coalesce into a fully fledged postcapitalist future or whether it is doomed to be stay marginal and transient at best. Anthropology can be at the forefront of this theoretical challenge. We close this brief commentary by addressing the importance of a future-oriented thinking in Anthropology and for the social science in general.
\end{abstract}

Keywords: capitalism; postcapitalism; alterity; future

\section{C: The Pillars of Capitalism}

We start with a working definition: capitalism is an economic system based on private property, production for the market, profit drivers, and state regulation. We are aware that this definition of capitalism does not do justice to a multifaced and elusive concept. This is just a practical, pragmatic starting point. We cannot here enter into an elaborated analysis about the different faces and subtleties of contemporary varieties of capitalism (for reference see [1]). However, endless debates continue between those who defend a progressive, entrepreneurial capitalism that unleashes human energies and solves problems and those who see in the ongoing commodification, human exploitation, and environmental destruction in the name of profit and markets enough reasons for dismantling the present system and striving for another one.

\section{2. $\neg$ C: Life Outside Capitalism}

Maybe the age where it was possible to smash capitalism with a revolution is gone, but forms of alterity to the current socio-economic system have never been so rich and present as now [2,3]. With the symbol $\neg \mathrm{C}$ (read: not-C), we indicate everything that opposes, avoids, rethinks, or dribble one or all the working logics of capitalism, be it in theory or in practices, in the academia or on the streets. $\neg \mathrm{C}$ is a messy galaxy with fuzzy boundaries. Injustices and rising inequalities between rich and poor do not stir masses nowadays, despite enlightened thinkers continuing to insist on it [4]. Much of the thrust to a renewed critical stance passes through environmental fears. The crucial focus is on the destructive effect of an endless economic growth, the exhaustion of natural resources and the commodification of everything, water included [5].

A variety of "degrowth" proposals are flourishing, from theoretically grounded ideas (bioregions, steady state, common goods, etc.) to more mundane forms of eco-consumeristic lifestyles or practices that circumvent the market exchange logic (DIY, permaculture, freeganism, etc.; on Wikipedia [6], the reader can find dozens of related sub-cultures). On the 
other hand, there is a growing awareness that living and working in advanced urban capitalist society exacerbates feelings of discomfort and the sense of precarity, anxiety, and alienation. The work-buy-consume-die destiny is no longer tenable for many. A variety of exit strategies are now intensely discussed in publications and internet fora [7]. When consciously realized, this can lead to life choices that embrace material frugality, less work, less money but more time dedicated to personal and spiritual growth, far from the noise of the city. This can pair existential needs with ecological ideals as well as the rediscovery of a sense of community and democracy that counters the individualist prevailing ethos. In this arena, we see that there is plenty of room for ethnographical and anthropological explorations, imagination, activism.

Often, $\neg \mathrm{C}$ does not present itself as such but is mantled with ecological, egalitarian, communitarian, humanitarian, anti-racist, or even psychological narratives. Sometimes, it is more an unconscious disposition than a rational proposal. Not all the elements of $\neg \mathrm{C}$ are necessarily progressive and solidaristic. Reactionary and populist responses to economic globalization perceived as a steamroller that annihilates local communities are common nowadays as well as violent forms of reactions and protest [8].

\section{Converging Lens? Or Eternal Periphery?}

Can this perceived social ferment, this fragmented and chaotic juxtaposition of good (but sometimes also bad) intentions and demand for change to a coherent whole in the future be generative of a different kind of society? The "converging lens" scenario (Figure 1) assumes that different parts of $\neg \mathrm{C}$ will be able to converge somehow in the future like rays of light, and to become a critical mass for change. What can play the role of the converging lens? An inspiring leader? A catastrophicevent? Can this transition be encouraged and guided? Can this happen in some regions of the world and not in others? These are issues open to different speculations. Fast communication technologies are fostering the creation of separate communities (each proposing its own idea of what it means to be part of $\neg \mathrm{C}$ ) but they seem to pushin the opposite direction: reinforcing closed, self-referencing echo chambers instead of open networks. Another scenario sees the postcapitalist islands remaining marginal, isolated, and/or regressively co-opted by the ever-changing capitalist engine. This may seem the most plausible scenario given the strong restoring forces that those in power can apply to maintain the established order. In any case, this cannot limit our imagination about the potential transformative role of this alterity. For us, one mission of social sciences such as Cultural Anthropology is to identify and interpret weak signals that can represent the seeds of change for the future. The world is confronting different global challenges (from environment to economy), and we perceive the need for more future-oriented theorization and imagination. The understanding of postcapitalist futures is not one possible research topic, but it should be, in our opinion, the research topic of our time.

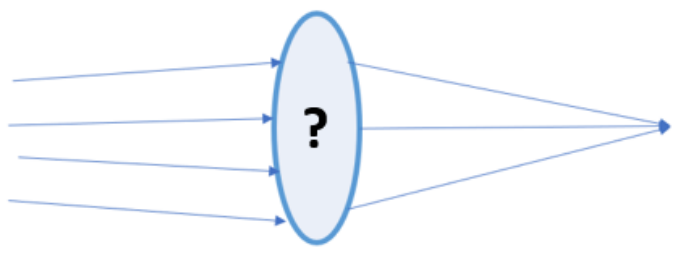

Figure 1. Converging lens towards a post-capitalist world? But which one?

Author Contributions: All authors have contributed to the different sections of this manuscript. All authors have read and agreed to the published version of the manuscript.

Funding: This research received no external funding.

Institutional Review Board Statement: Not Applicable.

Informed Consent Statement: Not applicable. 
Data Availability Statement: Not applicable.

Conflicts of Interest: The authors declare no conflict of interest.

\section{References}

1. Wolf, H. Capitalism. In Encyclopedia of Social Theory; Ritzer, G., Ed.; SAGE Publications, Inc.: Thousand Oaks, CA, USA, 2005; Volume 1, pp. 77-80.

2. Gibson-Graham, J.K. The End of Capitalism (As We Knew It); Blackwell: Oxford, UK, 1996.

3. Gibson-Graham, J.K. Postcapitalist Politics; Minnesota Press: Minneapolis, MN, USA; London, UK, 2006.

4. Wright, E.O. Envisioning Real Utopias; Verso: London, UK, 2010.

5. Harvey, D. The Enigma of Capital; Profile Books: London, UK, 2011.

6. Wikipedia Contributors. “Anti-Consumerism." Wikipedia, The Free Encyclopedia. Available online: https://en.wikipedia.org/ wiki/Anti-consumerism (accessed on 10 November 2021).

7. Hodgkinson, T. How to Be Free; Hamish Hamilton: London, UK, 2006; ISBN 9780241143216.

8. Achilles, M. Nationalism, Nativism, and the Revolt against Globalization. [Special Issue]. EuropeNow, 1//02/2018. Available online: https: / / www.europenowjournal.org/2018/01/31/nationalism-nativism-and-the-revolt-against-globalization/ (accessed on 22 October 2021). 